\title{
Is it possible to improve elderly male bladder function by having them drink more water? A randomized trial of effects of increased fluid intake/urine output on male lower urinary tract function.
}

Citation for published version (APA):

Spigt, M. G., van Schayck, C. P., Knipschild, P. G., Westerterp, K. R., van de Beek, C., van Kerrebroeck, P. E. V. A., Pel, J., van Mastrigt, R., \& Knottnerus, J. A. (2006). Is it possible to improve elderly male bladder function by having them drink more water? A randomized trial of effects of increased fluid intake/urine output on male lower urinary tract function. Urology, 68(5), 1031-1036. https://doi.org/10.1016/j.urology.2006.07.010

Document status and date:

Published: 01/01/2006

DOI:

10.1016/j.urology.2006.07.010

Document Version:

Publisher's PDF, also known as Version of record

Document license:

Taverne

Please check the document version of this publication:

- A submitted manuscript is the version of the article upon submission and before peer-review. There can be important differences between the submitted version and the official published version of record. People interested in the research are advised to contact the author for the final version of the publication, or visit the DOI to the publisher's website.

- The final author version and the galley proof are versions of the publication after peer review.

- The final published version features the final layout of the paper including the volume, issue and page numbers.

Link to publication

\footnotetext{
General rights rights.

- You may freely distribute the URL identifying the publication in the public portal. please follow below link for the End User Agreement:

www.umlib.nl/taverne-license

Take down policy

If you believe that this document breaches copyright please contact us at:

repository@maastrichtuniversity.nl

providing details and we will investigate your claim.
}

Copyright and moral rights for the publications made accessible in the public portal are retained by the authors and/or other copyright owners and it is a condition of accessing publications that users recognise and abide by the legal requirements associated with these

- Users may download and print one copy of any publication from the public portal for the purpose of private study or research.

- You may not further distribute the material or use it for any profit-making activity or commercial gain

If the publication is distributed under the terms of Article 25fa of the Dutch Copyright Act, indicated by the "Taverne" license above,

Download date: 26 Apr. 2023 


\title{
IS IT POSSIBLE TO IMPROVE ELDERLY MALE BLADDER FUNCTION BY HAVING THEM DRINK MORE WATER? A RANDOMIZED TRIAL OF EFFECTS OF INCREASED FLUID INTAKE/URINE OUTPUT ON MALE LOWER URINARY TRACT FUNCTION
}

\author{
MARK SPIGT, ONNO VAN SCHAYCK, PAUL KNIPSCHILD, KLAAS WESTERTERP, \\ CEES VAN DE BEEK, PHILIP VAN KERREBROECK, JOHAN PEL, RON VAN MASTRIGT, \\ AND ANDRÉ KNOTTNERUS
}

\begin{abstract}
Objectives. Several animal studies have shown that bladder performance improves as a result of diuresis. Whether increased urine output also has beneficial effects on elderly male bladder function and lower urinary tract symptoms is unknown.

Methods. We performed a randomized placebo-controlled trial of 141 men, 55 to 75 years of age, with moderate lower urinary tract symptoms. The experimental group drank $1.5 \mathrm{~L}$ of extra water daily. The control group consumed one tablespoon of placebo syrup daily. After 6 months, we evaluated bladder contractility, voided volumes, and the severity of lower urinary tract symptoms. The actual increase in water consumption was measured using the deuterium urine dilution method.

Results. Water consumption in the intervention group increased by $359 \mathrm{~mL}$ (95\% confidence interval [CI] 171 to 548) per 24 hours compared with the control group. At 6 months, no statistically significant effect was found in the maximal flow rate $(0.9 \mathrm{~mL} / \mathrm{s}, 95 \% \mathrm{Cl}-0.4$ to 2.2$)$ compared with placebo. A statistically significant effect was found for bladder pressure $\left(20 \mathrm{~cm} \mathrm{H}_{2} \mathrm{O}, 95 \% \mathrm{Cl} 6\right.$ to 34) and bladder wall stress (1.9 $\mathrm{N} / \mathrm{cm}^{2}, 95 \% \mathrm{Cl} 0.3$ to 3.5). In addition, it showed that the experimental group had greater maximal (44 mL, 95\% $\mathrm{Cl}-1$ to 90 ) and average ( $26 \mathrm{~mL}, 95 \% \mathrm{Cl} 1$ to 51 ) voided volumes per urination. The subjective effect parameters improved in both groups, but no statistically significant differences were found between the two groups.

Conclusions. It seems possible to improve some aspects of male bladder function by drinking more water. However, the effects are too small to be clinically relevant. UROLOGY 68: 1031-1036, 2006. (C) 2006 Elsevier Inc.
\end{abstract}

$T_{1}$ he aim of our research was to test a possible preventive intervention for lower urinary tract symptoms (LUTS) in elderly men. LUTS are present in approximately $20 \%$ to $30 \%$ of the elderly male population. ${ }^{1}$ Because of the high prevalence

This study was financed by the Dutch government by way of the Netherlands Organisation for Health Research and Development (ZonMw).

From the Departments of General Practice, Human Biology, and Urology, Maastricht University, Maastricht; Department of Urology, Erasmus MC, Rotterdam, The Netherlands

Reprint requests: Mark Spigt, Ph.D., Department of General Practice, Maastricht University, P.O. Box 616, Maastricht 6200 MD, The Netherlands. E-mail: m.spigt@hag.unimaas.nl

Submitted: January 18, 2006, accepted (with revisions): July 31, 2006 and the associated costs, the prevention of these symptoms is of great importance from a health policy perspective. ${ }^{2}$

Several animal studies have shown that bladder performance can be improved by increasing the urine output. ${ }^{3,4}$ It is assumed that this is an adaptive response to an increased physiologic load. This response is essentially different from the pathologic adaptation observed in the case of bladder outlet obstruction. ${ }^{5}$ In the latter, after an initial adaptation, a marked increase in bladder mass and a decrease in both compliance (flexibility) and contractility occur. ${ }^{5}$ In the case of increased diuresis, the animal bladder mass is also increased, but the compliance and contractility improve..$^{3,4}$

The animal study findings made us wonder 


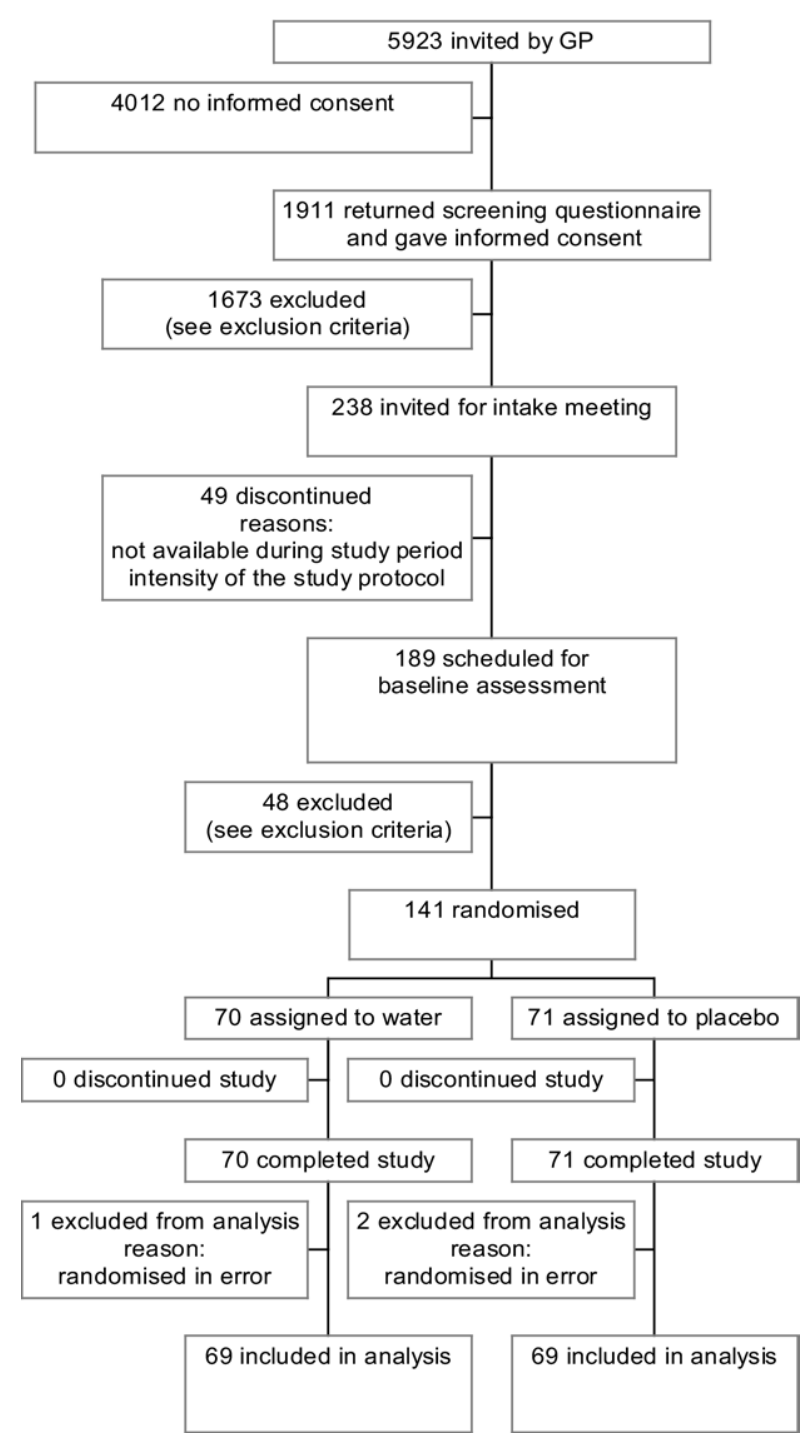

FIGURE 1. Trial profile.

whether it would be possible to improve the function of the human urinary tract by increasing the urine output. ${ }^{6}$ In humans, an increased urine output can be achieved by increasing the fluid intake. In a previously published uncontrolled study, we observed a gradual improvement in the maximal urinary flow rate and maximal and average voided volumes after 2 months of increased fluid intake. ${ }^{7}$ These preliminary findings seemed to support our hypothesis.

The next step was to study the long-term effects in a controlled study. We report on a randomized placebo controlled trial in which we studied the effects of increased fluid intake on elderly male lower urinary tract function and LUTS.

\section{MATERIAL AND METHODS}

\section{PARTICIPANTS}

The study population was recruited using 21 general practices. Figure 1 shows the trial profile of this study. The general practitioners invited their total male population between 55 and 75 years of age to participate. A screening questionnaire, containing the International Prostate Symptom Score (IPSS; range 0 to 35), ${ }^{8}$ questions on comorbidity, and a 24-hour drink diary, together with the informed consent documents, were enclosed with the doctor's invitation. A total of 1911 men gave informed consent and were screened for moderate LUTS (IPSS 8 to 19). The main exclusion criteria were the presence of mild (IPSS 0 to 7 ) or severe (IPSS 20 to 35) LUTS and a self-reported fluid intake greater than $2 \mathrm{~L} /$ day. The other exclusion criteria were the presence of diabetes, Parkinson's disease, or renal disease; previous surgery of the lower urinary tract; a history of prostate or bladder carcinoma; and the use of diuretics, medication for LUTS, or tricyclic antidepressive agents. We excluded 1673 men on the basis of these criteria. The remaining 238 men were invited for an intake visit and a baseline assessment. At this point, participants were excluded if no baseline assessment was possible (eg, inability to urinate in the presence of the assessor), if prostate cancer was diagnosed (prostate-specific antigen level greater than $4.0 \mu \mathrm{g} / \mathrm{L}$ followed by biopsy to confirm the presence of carcinoma), or if they had a serum sodium level less than $130 \mathrm{mmol} / \mathrm{L}$.

\section{RANDOMIZATION AND INTERVENTIONS}

A person, who was otherwise not involved in the execution of the study and had no access to the baseline data, generated the random allocation sequence with a computerized randomnumber generator and randomly assigned the participants to two groups. A person, who was not involved in the effect measurements, instructed the men in the intervention group to drink $1.5 \mathrm{~L}$ of water daily, in addition to their normally consumed beverages, for a 6-month period. They were advised to divide this amount into three portions of $0.5 \mathrm{~L}$ spread throughout the day. To improve the adherence to the intervention, they were supplied with $0.5-\mathrm{L}$ glasses. The control group received a placebo intervention in the form of placebo syrup (one tablespoon $[8 \mathrm{~mL}]$ ) each day during dinner, also for a 6-month period.

The participants were not given any information on the specific goal of the interventions to accomplish blinding of the nature of the interventions and the hypothesis of this study. A detailed description of the methodologic and ethical aspects of this trial has been previously published. ${ }^{9}$ The ethical review committee of the University Hospital Maastricht/University of Maastricht approved the research protocol and the informed consent procedure.

All parameters were recorded at baseline and at 6 months (immediately after termination of the intervention period).

\section{Objective Effect Parameters}

The objective measurements were conducted at the Maastricht University Hospital, Department of Urology. Seven participants were scheduled for each session, which lasted approximately 4 to 5 hours. We asked them to drink a lot of water during each session so that they would produce enough urine to void four times.

The maximal urinary flow rate (Qmax) was assessed two times by measuring the voided volume per unit of time with a Dantec flow meter. ${ }^{10}$ We calculated the mean of the measurements if both recorded voidings were valid (ie, voided volume greater than $150 \mathrm{~mL}$ ); otherwise only the valid measurement was included in the final analysis. Isovolumetric bladder pressure was assessed two times using the condom catheter method. ${ }^{11-13}$ In this procedure, the patient voids through a modified incontinence condom that is connected by way of a measurement unit to three tubes. Next, voiding is interrupted by closing the tubes, and the pressure inside the condom is measured. This pressure represents the isovolumetric bladder 
pressure. The maximal value attained in the two measurements was included in the analysis. Bladder wall thickness was assessed by ultrasonography by measuring the thickness of the anterior bladder wall. ${ }^{14,15}$ The measurements were performed two times using a Hitachi EUB 6000 with a 3.5-MHz probe. The thickness of the anterior bladder wall was measured at three points with the transducer suprapubically placed in the sagittal plane with each subject in supine position. We then calculated the mean of these three observations for each measurement and subsequently the mean of the two mean values. The measured thickness was not corrected for bladder volume. ${ }^{15}$

In addition, we measured the volume of the bladder before the measurement of the isovolumetric bladder pressure using the same ultrasound equipment. By combining the isovolumetric bladder pressure, bladder volume, and bladder wall thickness, the maximally generated bladder wall stress was calculated according to the method described by Bross et al. ${ }^{16}$ The postvoid residual urine volume was also assessed by ultrasound after each measurement of the Qmax. A mean of the two measurements was calculated. In addition to these measurements performed in the hospital, we calculated the maximal and average voided volume per urination from a 24-hour frequency volume chart. ${ }^{17}$

\section{Subjective EfFect Parameters}

The global perceived benefit of the intervention was measured with the question: "How did your urinary condition change since treatment initiation?" (7-point scale: $0=$ much worse to $6=$ much better). The scores were recoded into a 3 -point scale indicating worsening (score 0 to 2), no change (score 3), and improvement (score 4 to 6) of urinary tract function. Patients answered the IPSS questionnaire ${ }^{8}$ and quality-of-life question (range 0 to 6 ) to assess symptom severity and bother.

\section{ASSESSMENTS OF COVARIATES}

We classified the subjects into obstructed and nonobstructed patients by combining the Qmax with the isovolumetric bladder pressure using the following strategy: Qmax less than $4.5 \mathrm{~mL} / \mathrm{s}$ indicated obstructed; Qmax greater than $13.8 \mathrm{~mL} / \mathrm{s}$ indicated nonobstructed; and Qmax 4.5 to 13.8 $\mathrm{mL} / \mathrm{s}$ indicated obstructed if the measured bladder pressure was greater than $36.4+5.8 \times$ Qmax. This method has been described by Pel et al. ${ }^{18}$ Obstruction was used as a stratification factor in the randomization procedure. In addition, we measured the prostate size using a $6.5-\mathrm{MHz}$ rectal probe.

\section{ASSESSMENT OF ADHERENCE}

We measured the adherence to the experimental intervention with deuterium-labelled water. The deuterium method is considered the reference standard for measuring water turnover in humans. ${ }^{19,20}$ After ingestion, deuterium mixes with the total body water and is eliminated at a rate dependent on the rate of water turnover. Therefore, by plotting the deuterium concentration in the urine against time, we were able to determine the total water turnover per 24 hours. The experimental and control groups followed the deuterium protocol for 2 weeks before the baseline assessment in the hospital and during the final 2 weeks of the intervention period.

\section{SAMPLE SizE}

With an assumed standard deviation (SD) of 5.2 (derived from el Din et al. ${ }^{21}$ ), we needed 68 patients per group to detect a clinically worthwhile effect of $2.5 \mathrm{~mL} / \mathrm{s}$ on Qmax ( 0.9 power, alpha $=0.05$, two-sided). With this sample size, we were able to detect a difference of 1.5 points on the IPSS (assumed SD
3.221). A total of 141 participants were enrolled in the study (Fig. 1). Three subjects were ineligible because they had a baseline IPSS score greater than the maximum of 19 points (score of 20, 21, and 22). They were, therefore, excluded from the final statistical analysis.

\section{Statistical ANALYSIS}

For the estimation of the treatment effect, we performed multiple linear regression analyses (analysis of covariance) in which the follow-up measurement was used as the outcome variable, the intervention type as the predictive variable, and the baseline score of that outcome variable, prostate size, and age as covariates. ${ }^{22,23}$ The randomization code was revealed to the researchers after the first main statistical analyses were performed. We used an intent-to-treat analysis and the Statistical Package for Social Sciences (SPSS, Chicago, Ill). As a per protocol analysis, the analysis was subsequently done without the subjects in the experimental intervention group who had not increased their water turnover greater than the median (intervention group) level. In addition, we studied the linear relationship between the effect measures and actual increase in water turnover (linear regression analysis). We determined the 95\% confidence intervals, and a two-tailed $P$ value less than 0.05 was considered statistically significant.

\section{RESULTS}

\section{OBJeCTIVE EFFECTS}

The effects of the experimental intervention on the bladder are shown in Table I. At 6 months, no statistically significant effect of increased water intake was found on Qmax compared with placebo, but the intervention group scored better on two other measures of bladder contractility-bladder pressure and bladder wall stress. No statistically significant effect was found on bladder wall thickness or postvoid residual urine volume.

In terms of the storage function of the bladder, it showed that the experimental group had greater maximal, as well as average, voided volumes per urination at 6 months; the effect on the average voided volume was statistically significant.

\section{SubjeCtive EFFECTS}

At 6 months, 7 men (10\%) in the experimental group reported a worsening and 42 men (61\%) reported an improvement of their urinary function compared with $5(7 \%)$ and $34(49 \%)$ in the control group (chi-square $P=0.2$; data not shown in Table I). Both groups had a lower total IPSS and IPSS quality of life score at 6 months. The mean irritative score decreased significantly more in the placebo group and the obstructive symptoms changed insignificantly in favor of the experimental group.

\section{TREATMENT ADHERENCE}

The 24-hour water turnover in the experimental group increased by $1030 \pm 586 \mathrm{~mL}$ from $3034 \pm$ $631 \mathrm{~mL}$ at baseline (data not shown). The water turnover in the control group was $2950 \pm 498 \mathrm{~mL}$ at baseline and was $672 \pm 443 \mathrm{~mL}$ greater at 6 
TABLE I. Changes in effect parameters between increased water intake and control

\begin{tabular}{|c|c|c|c|c|}
\hline Variable & $\begin{array}{l}\text { Control } \\
(n=69)\end{array}$ & $\begin{array}{c}\text { Water } \\
(n=69)\end{array}$ & $\begin{array}{c}\text { Effect of Water* } \\
(95 \% \mathrm{CI})\end{array}$ & $P$ Value \\
\hline \multicolumn{5}{|c|}{ Objective effect parameters } \\
\hline \multicolumn{5}{|c|}{ Maximal urine flow rate $(\mathrm{mL} / \mathrm{s})$} \\
\hline Baseline & $17.5(6.8)$ & $15.8(5.6)$ & & \\
\hline $6 \mathrm{mo}$ & $16.3(6.5)$ & $15.8(5.4)$ & $0.9(-0.4$ to 2.2$)$ & 0.2 \\
\hline \multicolumn{5}{|c|}{ Isovolumetric bladder pressure $\left(\mathrm{cm} \mathrm{H}_{2} \mathrm{O}\right)$} \\
\hline Baseline & $124(45)$ & $128(53)$ & & \\
\hline $6 \mathrm{mo}$ & $110(40)$ & $131(58)$ & $20(6-34)$ & 0.007 \\
\hline \multicolumn{5}{|c|}{ Bladder wall thickness (mm) } \\
\hline Baseline & $1.9(0.3)$ & $1.9(0.3)$ & & \\
\hline $6 \mathrm{mo}$ & $2.1(0.3)$ & $2.1(0.3)$ & $0.03(-0.1$ to 0.1$)$ & 0.6 \\
\hline \multicolumn{5}{|c|}{ Bladder wall stress $\left(\mathrm{N} / \mathrm{cm}^{2}\right)$} \\
\hline Baseline & $13.8(5.5)$ & $13.4(5.8)$ & & \\
\hline $6 \mathrm{mo}$ & $11.5(4.7)$ & $12.9(5.7)$ & $1.9(0.3-3.5)$ & 0.02 \\
\hline \multicolumn{5}{|c|}{ Postvoid residual urine volume (mL) } \\
\hline Baseline & $168(113)$ & $134(107)$ & & \\
\hline $6 \mathrm{mo}$ & 169 (123) & $143(117)$ & $-5(-39$ to 29$)$ & 0.8 \\
\hline \multicolumn{5}{|c|}{ Maximal voided volume per urination $(\mathrm{mL})$} \\
\hline Baseline & $351(117)$ & $345(132)$ & & \\
\hline $6 \mathrm{mo}$ & $337(135)$ & $381(138)$ & $44(-1$ to 90$)$ & 0.05 \\
\hline \multicolumn{5}{|c|}{ Average voided volume per urination (mL) } \\
\hline Baseline & $218(78)$ & 205 (75) & & \\
\hline $6 \mathrm{mo}$ & $206(87)$ & $226(65)$ & $26(1-51)$ & 0.04 \\
\hline \multicolumn{5}{|c|}{ Subjective effect parameters } \\
\hline \multicolumn{5}{|c|}{ Symptoms (IPSS; 0-35) } \\
\hline Baseline & $13.4(3.1)$ & $12.2(3.3)$ & & \\
\hline $6 \mathrm{mo}$ & $11.2(4.3)$ & $11.1(4.2)$ & $0.5(-0.9$ to 2.0$)$ & 0.5 \\
\hline \multicolumn{5}{|c|}{ Irritative symptoms (IPSS items 2, 4, 7; 0-15) } \\
\hline Baseline & $5.7(2.8)$ & $6.0(2.6)$ & & \\
\hline $6 \mathrm{mo}$ & $4.4(2.5)$ & $5.8(2.5)$ & $1.3(0.6-2.1)$ & $<0.001$ \\
\hline \multicolumn{5}{|c|}{ Obstructive symptoms (IPSS items $1,3,5,6$; 0-20) } \\
\hline Baseline & $7.7(2.8)$ & $6.2(2.8)$ & & \\
\hline $6 \mathrm{mo}$ & $6.8(3.4)$ & $5.2(2.6)$ & $-0.7(-1.7$ to 0.2$)$ & 0.139 \\
\hline \multicolumn{5}{|c|}{ IPSS Quality of Life (0-6) } \\
\hline Baseline & $2.9(1.0)$ & $2.6(1.0)$ & & \\
\hline $6 \mathrm{mo}$ & $2.5(1.2)$ & $2.3(0.9)$ & $0.1(-0.2$ to 0.4$)$ & 0.6 \\
\hline
\end{tabular}

months. The effect of the experimental intervention compared with the placebo was $359 \mathrm{~mL}$ (95\% confidence interval 171 to 548).

\section{Per Protocol Analysis}

Excluding the participants from the experimental group who had a water turnover of less than the median score of $955 \mathrm{~mL}$ did not increase the effects (effect of water on Qmax, $0.7 \pm 0.9 \mathrm{~mL} / \mathrm{s}$; on bladder pressure, $15 \pm 9 \mathrm{~cm} \mathrm{H}_{2} \mathrm{O}$; on IPSS, $0.8 \pm 0.9$ ). In addition, it showed that changes in the Qmax, isovolumetric bladder pressure, and IPSS could not be predicted by changes in water turnover (coefficients for 1-L increase in water turnover: Qmax, $1.0 \pm 0.7 \mathrm{~mL} / \mathrm{s}$, bladder pressure, $-1.4 \pm 7.6 \mathrm{~cm}$ $\mathrm{H}_{2} \mathrm{O}$; IPSS $-0.09 \pm 0.7$ ).

\section{Analysis of Effect Modification of Age AND OBSTRUCTION}

The interaction terms for obstruction and age were not statistically significant for all outcome measures, indicating that the effect of the intervention was not significantly different for the obstructed versus nonobstructed participants or for the older versus younger participants (data not shown). In addition, no clinically relevant differences between the age and obstruction subgroups were observed in the stratified analyses for the effects on Qmax, bladder pressure, and IPSS (data not shown).

\section{COMMENT}

The results of animal studies formed the basis of our hypothesis that the human bladder could fa- 
vorably adapt to increased loading. There was no reason to assume that animal-like effects would not be possible in humans. In addition to these animal studies, the results of an uncontrolled study of 44 elderly men showed positive effects and therefore seemed to confirm our ideas. ${ }^{7}$ In this trial, 6 months after we gave the advice to increase the daily fluid intake by $1.5 \mathrm{~L}$, we found some statistically significant, but modest, effects on bladder function. No important effects were found on the subjective effect parameters.

It has been shown that many urologists (69\%) use lifestyle interventions in the treatment of LUTS. ${ }^{24}$ Such advice may include fluid restriction, caffeine or alcohol avoidance, rescheduling medication such as diuretics, retraining of "bad" voiding habits, and many other instructions. ${ }^{24}$ However, at present, these instructions seem to be based on clinical experience or findings from etiologic studies, because we found no randomized trials in which the effects of self-management as an intervention for men with LUTS were investigated. Only one study was found that made an attempt to construct a self-management program. ${ }^{25}$ Because LUTS is more of a functional, than an anatomic, disorder, we believe that self-management interventions should be investigated more often.

An important limitation of our study was the relatively poor contrast between the two study groups. This may partly explain the relatively small effects. In the animal studies, using diuretics, a $200 \%$ to $300 \%$ increase in urine output was achieved. ${ }^{3,4}$ In our study, we accomplished a contrast of approximately $10 \%$ at the end of the study. This contrast might have been larger if the Dutch summer of 2003 had not been the second warmest summer in the past 100 years. The hot summer increased the water turnover in the control group, reducing the contrast between the two groups.

Despite the poor contrast, we observed some statistically significant effects. It seems, therefore, that the bladder responded; although the observed effects were not clinically relevant. Future studies on the adaptive capability of the bladder must put much effort in achieving a more profound contrast. Another approach that might improve the adaptability of the bladder is to improve the bladder blood flow. The reduced vascularization and innervation of the elderly bladder ${ }^{26,27}$ probably impairs the adaptive capacity. Some evidence has suggested that alphablockers $^{28}$ and aspirin ${ }^{29}$ improve bladder blood flow. These agents might be used in combination with increased urine output to improve the adaptive capability of the bladder.

\section{CONCLUSIONS}

It seems possible to improve elderly male bladder function by increased physiologic loading, but the method we used to increase the urine output (ie, to drink $1.5 \mathrm{~L}$ of water) produced effects that were too small. Future research should focus on finding ways to achieve a large increase in urine output without compromising the feasibility of the intervention.

Acknowledgment. To Ellen de Goeij for her assistance in the effect measurements, Loek Wouters for performing the deuterium analyses, and Willem de Goeij for his assistance in the data collection by designing a structured database.

\section{REFERENCES}

1. Bosch JL, Hop WC, Kirkels WJ, et al: The International Prostate Symptom Score in a community-based sample of men between 55 and 74 years of age: prevalence and correlation of symptoms with age, prostate volume, flow rate and residual urine volume. Br J Urol 75: 622-630, 1995.

2. Roehrborn CG: Acute relief or future prevention: is urology ready for preventive health care? Urology 56: 12-19, 2000.

3. Tammela TL, Longhurst PA, Wein AJ, et al: The effect of furosemide-induced diuresis on rabbit micturition and bladder contractile function. J Urol 150: 204-208, 1993.

4. Ohnishi N, Horan P, Levin SS, et al: Sucrose diuresis protects rat bladder from outlet partial obstruction-induced contractile dysfunction. Urology 54: 183-187, 1999.

5. Levin RM, Levin SS, Zhao Y, et al: Cellular and molecular aspects of bladder hypertrophy. Eur Urol 32(suppl 1): $15-21,1997$.

6. Spigt MG, van Schayck CP, van Kerrebroeck PE, et al: Pathophysiological aspects of bladder dysfunction: a new hypothesis for the prevention of "prostatic" symptoms. Med Hypothes 62: 448-452, 2004.

7. Spigt MG, Knottnerus JA, van de Beek C, et al: Shortterm effects of increased urine output on male bladder function and lower urinary tract symptoms. Urology 64: 499-503, 2004.

8. Barry MJ, Fowler FJ Jr, O'Leary MP, et al, for the Measurement Committee of the American Urological Association: The American Urological Association symptom index for benign prostatic hyperplasia. J Urol 148: 1549-1557, 1992.

9. Spigt MG, Knipschild P, van Schayck CP, et al: The validity and ethics of giving placebo in a randomized nonpharmacologic trial was evaluated. J Clin Epidemiol 58: 350-356, 2005.

10. Jensen KM: Uroflowmetry in elderly men. World J Urol 13: 21-23, 1995.

11. van Mastrigt R, and Pel JJ: Towards a noninvasive urodynamic diagnosis of infravesical obstruction. BJU Int 84: 195-203, 1999.

12. Pel JJ, and van Mastrigt R: Non-invasive measurement of bladder pressure using an external catheter. Neurourol Urodyn 18: 455-469, 1999.

13. Huang Foen Chung JW, Bohnen AM, Pel JJ, et al: Applicability and reproducibility of condom catheter method for measuring isovolumetric bladder pressure. Urology 63: 5660, 2004.

14. Kojima M, Inui E, Ochiai A, et al: Noninvasive quantitative estimation of infravesical obstruction using ultrasonic measurement of bladder weight. J Urol 157: 476-479, 1997.

15. Hakenberg OW, Linne C, Manseck A, et al: Bladder wall thickness in normal adults and men with mild lower urinary 
tract symptoms and benign prostatic enlargement. Neurourol Urodyn 19: 585-593, 2000.

16. Bross S, Schumacher S, Scheepe JR, et al: Combined evaluation of detrusor pressure and bladder wall thickness as a parameter for the assessment of detrusor function: an experimental in vivo study. J Urol 166: 1130-1135, 2001.

17. Gisolf KW, van Venrooij GE, Eckhardt MD, et al: Analysis and reliability of data from 24-hour frequency-volume charts in men with lower urinary tract symptoms due to benign prostatic hyperplasia. Eur Urol 38: 45-52, 2000.

18. Pel JJ, Bosch JL, Blom JH, et al: Development of a non-invasive strategy to classify bladder outlet obstruction in male patients with LUTS. Neurourol Urodyn 21: 117125,2002

19. Westerterp KR, Wouters L, and van Marken Lichtenbelt WD: The Maastricht protocol for the measurement of body composition and energy expenditure with labeled water. Obes Res 3(suppl 1): 49-57, 1995.

20. Westerterp KR: Body composition, water turnover and energy turnover assessment with labelled water. Proc Nutr Soc 58: 945-951, 1999.

21. el Din KE, Kiemeney LA, de Wildt MJ, et al: Correlation between uroflowmetry, prostate volume, postvoid residue, and lower urinary tract symptoms as measured by the International Prostate Symptom Score. Urology 48: 393397, 1996
22. Vickers AJ, and Altman DG: Statistics notes: analysing controlled trials with baseline and follow up measurements. BMJ Clin Res Ed 323: 1123-1124, 2001.

23. Twisk J, and Proper K: Evaluation of the results of a randomized controlled trial: how to define changes between baseline and follow-up. J Clin Epidemiol 57: 223-228, 2004.

24. Brown CT, van der Meulen J, Mundy AR, et al: Lifestyle and behavioural interventions for men on watchful waiting with uncomplicated lower urinary tract symptoms: a national multidisciplinary survey. BJU Int 92: 53-57, 2003.

25. Brown CT, van der Meulen J, Mundy AR, et al: Defining the components of a self-management programme for men with uncomplicated lower urinary tract symptoms: a consensus approach. Eur Urol 46: 254-262, 2004.

26. Saito M, Ohmura M, and Kondo A: Effect of ageing on blood flow to the bladder and bladder function. Urol Int 62: 93-98, 1999.

27. Tarcan T, Azadzoi KM, Siroky MB, et al: Age-related erectile and voiding dysfunction: the role of arterial insufficiency. Br J Urol 82(suppl 1): 26-33, 1998.

28. Das AK, Leggett RE, Whitbeck C, et al: Effect of doxazosin on rat urinary bladder function after partial outlet obstruction. Neurourol Urodyn 21: 160-166, 2002.

29. Schröder A, Levin RM, Kogan BA, et al: Aspirin treatment improves bladder function after outlet obstruction in rabbits. Urology 58: 608-613, 2001. 